\title{
The safety and feasibility of early postoperative oral nutrition on the first postoperative day after gastrectomy for gastric carcinoma
}

\author{
Oh Jeong $\cdot$ Seong Yeop Ryu $\cdot$ Mi Ran Jung $\cdot$ \\ Won Wong Choi $\cdot$ Young Kyu Park
}

Received: 27 January 2013/Accepted: 23 May 2013/Published online: 15 June 2013

(C) The International Gastric Cancer Association and The Japanese Gastric Cancer Association 2013

\begin{abstract}
Background Unlike the wide acceptance of early enteral nutrition after colorectal surgery, little information is available regarding the feasibility of immediate oral nutrition after gastric cancer surgery. This study evaluated the feasibility and safety of oral nutrition on the first postoperative day after gastrectomy.

Methods From September 2010 to March 2011, 74 consecutive gastric cancer patients received an oral diet on the first postoperative day after gastrectomy. Surgical outcomes, including hospital stay, morbidity, and mortality, were compared with a conventional diet group $(n=96$, before September 2010), in which an oral diet was started on the third or fourth postoperative day.

Results No significant differences were found in the clinicopathological characteristics or operation types between the two groups. Average diet start times in the early diet (ED) and conventional diet (CD) groups were 1.8 and. 3.2, respectively $(p<0.001)$. The mean hospital stay was significantly shorter in the ED group (7.4 vs. 8.9 days, $p=0.004)$. There was no significant difference in postoperative morbidity ( $p=0.947$ ) between the two groups. Gastrointestinal-related complications, such as anastomosis leakage or postoperative ileus, were also similar in the two
\end{abstract}

O. Jeong $(\bowtie) \cdot$ S. Y. Ryu · M. R. Jung · Y. K. Park

Division of Gastrointestinal Surgery, Department of Surgery, Chonnam National University Hwasun Hospital, 160 Ilsim-ri, Hwasun-eup, Hwasun-gun, Jeollanam-do 519-809, South Korea e-mail: surgeonjeong@gmail.com

Y. K. Park

e-mail: parkyk@jnu.ac.kr

W. W. Choi

Department of Surgery, Dong-guk University Ilsan Hospital, Goyang, South Korea groups. Overall compliance to early oral nutrition in the ED group was $78.5 \%$, and an old age ( $\geq 70$ years) was found to affect the compliance to early postoperative oral nutrition.

Conclusions Postoperative oral nutrition is safe and feasible on the first postoperative day after gastrectomy. However, elderly patients require careful monitoring when applying early oral nutrition after gastrectomy.

Keywords Stomach neoplasm · Gastrectomy · Enteral nutrition $\cdot$ Feasibility study $\cdot$ Diet

\section{Introduction}

Catabolic response after surgery may have detrimental effects, for example, it can compromise immune function, diminish muscle strength, delay wound healing, cause a subjective feeding of fatigue, prolong convalescence, and increase overall morbidity [1]. Prolonged postoperative starvation could further jeopardize malnutrition and catabolism, but nonetheless, the traditional view was that the oral intake of fluids or nutrients be reserved until postoperative ileus has resolved. After many reports were issued on the benefits of enteral nutrition in critically ill patients [2, 3], several experimental and clinical studies of gastrointestinal surgery have shown that traditional postoperative oral intake restriction is not based on scientific evidence. A number of recent randomized controlled trials and meta-analyses comparing early enteral nutrition and traditional postoperative fasting after gastrointestinal surgery have concluded that early postoperative enteral nutrition reduces postoperative morbidity (especially infectious complications), mortality, and hospital stay without increasing the risk of gastrointestinal-related complications [4-6]. 
Fast-track surgery, also known as "enhanced recovery after surgery (ERAS)" or "multimodal rehabilitation", refers to the use of multimodal approaches aimed at enhancing postoperative recovery and reducing morbidity by implementing scientific evidence related to anesthesia, analgesia, surgical stress, fluid management, minimally invasive surgery, nutrition, and ambulation [7]. Recently, several guidelines for different types of surgery including colonic, pancreatic, and pelvic surgery, have been issued from the ERAS society (available at http://www.eras society.org). Actually, early postoperative enteral nutrition is considered one of the most important multimodal approaches in the context of enhancing postoperative recovery [8]. However, unlike the wide acceptance of early oral nutrition after colorectal surgery [9], little data is available on the feasibility and safety of immediate postoperative oral nutrition after gastric surgery.

According to surveys conducted in Asia and Europe, many institutions still adhere to 3-4 days of postoperative fasting after gastrectomy, which is often accompanied by decompression of the stomach and the administration of a large amount of intravenous fluid [10, 11]. Furthermore, proponents of traditional postoperative fasting after gastrectomy often cite concerns of anastomosis safety and aspiration pneumonia. Recently, small retrospective studies [12, 13] and a randomized controlled trial [14] have found that early oral nutrition after gastrectomy is both beneficial and feasible. However, few studies have examined an immediate oral nutrition starting on the first postoperative day after gastrectomy. Therefore, the aim of this study was to evaluate the feasibility and safety of early postoperative oral nutrition on the first postoperative day after gastrectomy.

\section{Methods}

Patients

Our institution has been trying to standardize perioperative cares for gastric cancer patients, a process also known as "enhanced recovery after surgery" (ERAS) or "fast-track surgery". More specifically, main elements of perioperative care, such as, anesthesia, analgesia, postoperative intravenous fluid administration, abdominal drainage, nasogastric tube, and postoperative nutrition, were systemically reviewed and revised in clinical practice on a step-by-step basis, in accord with consensus and available scientific evidence.

As for postoperative nutrition, early oral nutrition on the first operative day began to be implemented to the patients undergoing gastrectomy beginning from September 2010, while previous diet regimen had consisted of supplying oral nutrition after 3-4 days of postoperative fasting. In the present study, the study group consisted of 74 consecutive gastric cancer patients who were managed by early postoperative oral nutrition (early diet (ED) group) after gastrectomy from September 2010 to March 2011. Ninety-six patients with conventional postoperative nutrition prior to the implementation of the early oral nutrition (before September 2010) were selected as a control group (conventional diet (CD) group) (Fig. 1). Patients with following reasons were not included in the present study; non-resectional or bypass surgery, an emergency operation (due to perforation or bleeding), gastric carcinoma in the remnant stomach, the presence of another malignant disease, or preoperative chemotherapy.
Fig. 1 Schematic diagram of the patients included in the present study

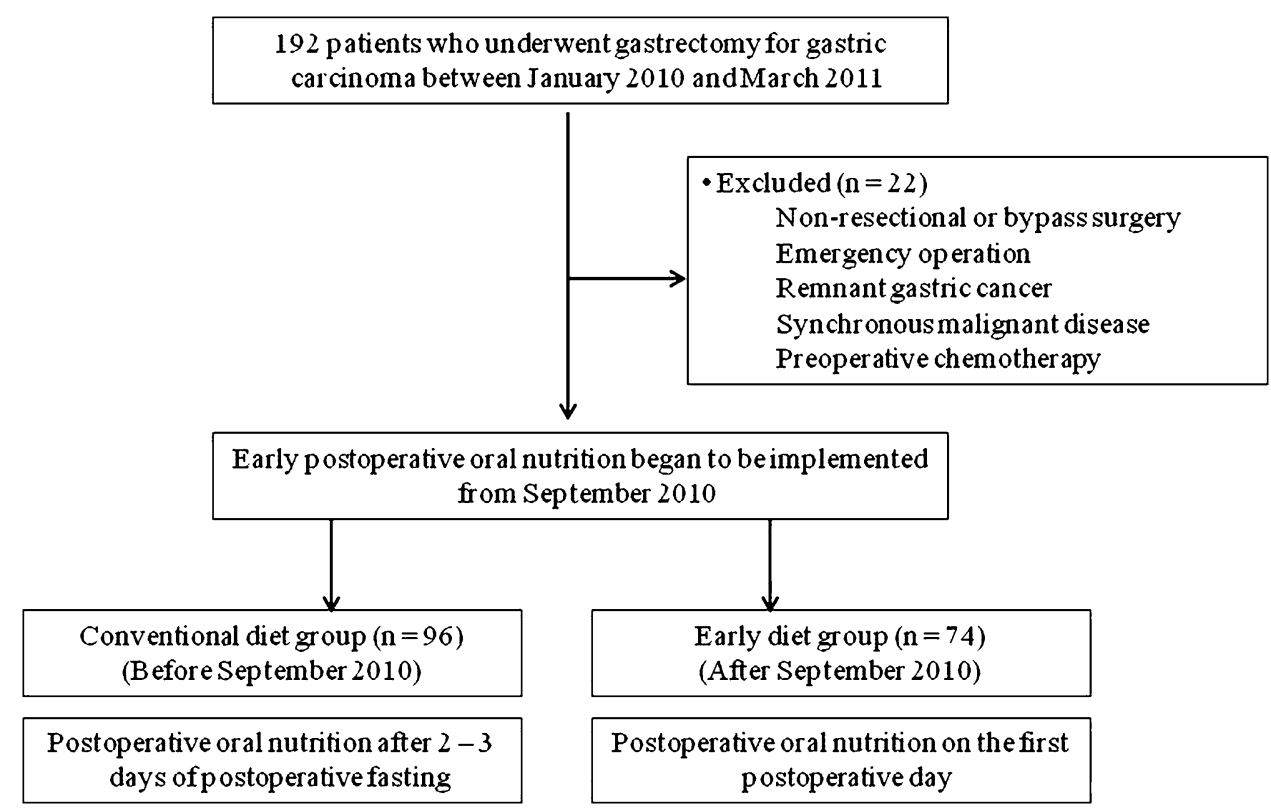


Demographic features, operative procedures, pathological results, hospital courses, and postoperative complications were retrospectively reviewed using prospectively collected data. Time to diet start was defined as the postoperative day when a patient began to eat an oral diet without interruption, and length of hospital stay was defined as time from surgery to hospital discharge. Regarding postoperative complications, a local complication was defined as a complication near the operation field and a systemic complication as a complication not associated with the operation filed. Types of complications were recorded according to our institutional guideline on the diagnosis of complications [15], and its severities were graded based on the Clavien-Dindo classification of surgical complication [16]. Every complication was reviewed by all members of our department at monthly consensus meetings.

\section{Operative procedures}

Patients underwent distal or total gastrectomy with regional lymph node dissection as defined by the Japanese Gastric Cancer Treatment guidelines [17]. Gastrectomy with D2 lymph node dissection was used as the standard procedure for advanced gastric cancer, and D1+ lymph node dissection was used to treat early gastric cancer. Choices between laparoscopic and open surgery were made based on preoperative stage (cT1-2/N0 or cT1N1 for laparoscopic surgery). After distal gastrectomy, Billroth I reconstruction was performed in most cases, and Billroth II or Roux-en Y gastrojejunostomy was performed in selected cases, such as, in those requiring wide resection of the stomach. After total gastrectomy, Roux-en Y esophagojejunostomy was performed using a circular stapler in all cases.

\section{Perioperative care}

Patients in the both groups were managed perioperatively using a same standardized clinical pathway protocol except for postoperative nutrition. For example, preoperative mechanical bowel cleansing was not performed, and prophylactic antibiotics were administered immediately before skin incision and continued until the first postoperative day. Routine insertion of a nasogastric tube or abdominal drain was avoided. Epidural anesthesia (fentanyl citrate $1000 \mu \mathrm{g}+$ levobupivacaine $200 \mathrm{mg}+$ normal saline $200 \mathrm{ml}, 2.5-3 \mathrm{ml} / \mathrm{h}$ ) was used for pain control and maintained for 3-4 days after surgery. No additional opioid drugs were used postoperatively, and nonsteroidal antiinflammatory drugs, such as ketorolac or diclofenac, were additionally used if patients complained of severe postoperative pain. In the ED group, intravenous fluid was restricted to a minimal daily requirement (20-25 ml/kg/day of parenteral nutritional solution) during the first three postoperative days. Additional intravenous fluid was administered when patient showed poor oral intake of water or food at the discretion of surgeons. The $\mathrm{CD}$ group usually received $40-50 \mathrm{ml} / \mathrm{kg} / \mathrm{day}$ of intravenous fluid administration until they resume an oral diet.

As for postoperative oral nutrition, members of the ED group started water intake early in the morning on the first postoperative day. When patients were judged to be able to consume water without abdominal discomfort or nausea and vomiting, and they were provided a soft meal (rice porridge) from the lunch menu (small amounts six times a day). Members of the CD group started an oral diet from the third or fourth postoperative days depending on bowel recovery and gastrointestinal symptoms. No additional feeding, such as enteral tube feeding, was given to both of the two groups.

Hospital discharge was decided upon based on consideration of the following criteria; (1) no requirement for intravenous medication or fluid or bedside care, (2) no laboratory or clinical sign of a complication, (3) tolerable pain with no or only oral analgesics, (4) the ability to fully ambulate without assistance, (5) the ability to eat more than half of given meal without adverse gastrointestinal symptoms, and (6) a willingness to go home.

\section{Statistical analysis}

The Student's $t$ test and the Mann-Whitney $U$ test were used to compare continuous variables, and the Chi-squared test and Fisher's exact test (as appropriate) were used to compare categorical variables. Group postoperative outcomes, including time to first flatus, diet start time, duration of hospital stay, reoperation, and morbidity and mortality, were compared. Postoperative outcomes were also compared with respect to operative procedures, such as, extent of gastric resection, operative approach, and lymph node dissection. Multivariate analysis was conducted using a logistic regression model to identify factors affecting compliance with early oral nutrition. Two-sided $p$ values of $<0.05$ were considered statistically significant, and the analyses were performed using SPSS version 16.0 for Windows (SPSS, Inc, Chicago, IL, USA).

\section{Results}

Table 1 summarizes the clinicopathological characteristics of the ED and CD groups. No significant intergroup differences were found with respect to ages, genders, body mass indices (BMI), comorbidities, or American Society of Anesthesiologists (ASA) scores, or with respect to operative procedures, such as, resection type, extent of lymph 
Table 1 Clinicopathological characteristics

\begin{tabular}{|c|c|c|c|}
\hline & $\begin{array}{l}\text { ED group } \\
(n=74)\end{array}$ & $\begin{array}{l}\text { CD group } \\
(n=96)\end{array}$ & $p$ \\
\hline Age, years (mean $\pm \mathrm{SD}$ ) & $59.9 \pm 11.6$ & $61.2 \pm 11.9$ & 0.476 \\
\hline Gender & & & 0.549 \\
\hline Male & $54(73.0)$ & $66(68.8)$ & \\
\hline Female & $20(27.0)$ & $30(31.3)$ & \\
\hline BMI, $\mathrm{kg} / \mathrm{m}^{2}($ mean $\pm \mathrm{SD})$ & $23.5 \pm 3.0$ & $23.5 \pm 3.0$ & 0.964 \\
\hline Comorbidity & $17(23.0)$ & $21(21.9)$ & 0.865 \\
\hline ASA score & & & 0.638 \\
\hline 1 & $24(32.4)$ & $31(32.3)$ & \\
\hline 2 & $48(64.9)$ & $59(61.5)$ & \\
\hline 3 & $2(2.7)$ & $6(6.3)$ & \\
\hline Resection type & & & 0.355 \\
\hline Distal gastrectomy & $62(83.8)$ & $75(78.1)$ & \\
\hline Total gastrectomy & $12(16.2)$ & $21(21.9)$ & \\
\hline Operative approach & & & 0.146 \\
\hline Open & $25(33.8)$ & $43(44.8)$ & \\
\hline Laparoscopy & $49(66.2)$ & $53(55.2)$ & \\
\hline Lymph node dissection & & & 0.427 \\
\hline $\mathrm{D} 1+$ & $49(66.2)$ & $69(71.9)$ & \\
\hline D2 & $25(33.8)$ & $27(28.1)$ & \\
\hline Combined organ resection & $6(8.1)$ & $9(9.4)$ & 0.773 \\
\hline Gall bladder & 5 & 4 & \\
\hline Spleen & 1 & 3 & \\
\hline Pancreas & 0 & 1 & \\
\hline Colon & 0 & 1 & \\
\hline Depth of invasion $^{\mathrm{a}}$ & & & 0.240 \\
\hline T1a & 33 (44.6) & $42(43.8)$ & \\
\hline $\mathrm{T} 1 \mathrm{~b}$ & 13 (17.6) & $27(28.1)$ & \\
\hline $\mathrm{T} 2$ & $11(14.9)$ & $6(6.3)$ & \\
\hline $\mathrm{T} 3$ & $9(12.2)$ & $9(9.4)$ & \\
\hline $\mathrm{T} 4 \mathrm{a}$ & $8(10.8)$ & $12(12.5)$ & \\
\hline Lymph node metastasis ${ }^{\mathrm{a}}$ & & & 0.588 \\
\hline No & $56(75.7)$ & $75(78.1)$ & \\
\hline N1 & $2(2.7)$ & $6(6.3)$ & \\
\hline $\mathrm{N} 2$ & $5(6.8)$ & $6(6.3)$ & \\
\hline N3a & $7(9.5)$ & $4(4.2)$ & \\
\hline $\mathrm{N} 3 \mathrm{~b}$ & $4(5.4)$ & $5(5.2)$ & \\
\hline
\end{tabular}

Numbers in parentheses are percentages

$E D$ group early diet group, $C D$ group conventional diet group, $B M I$ body mass index, ASA score American Society of Anesthesiologists score

a The 7th edition of UICC/AJCC TNM stage

node dissection, operative approach, or combined organ resection. Pathological examinations revealed similar distributions of invasion depth and lymph node metastasis (as defined by the seventh edition of the UICC/AJCC TNM classification) in the two groups.
Table 2 Postoperative outcomes

\begin{tabular}{llll}
\hline & $\begin{array}{l}\text { ED group } \\
(n=74)\end{array}$ & $\begin{array}{l}\text { CD group } \\
(n=96)\end{array}$ & $p$ \\
\hline $\begin{array}{l}\text { Time to first flatus, days } \\
(\text { mean } \pm \text { SD) }\end{array}$ & $2.7 \pm 1.3$ & $2.6 \pm 1.0$ & 0.524 \\
$\begin{array}{l}\text { Time to oral diet, days } \\
(\text { mean } \pm \text { SD) }\end{array}$ & $1.8 \pm 1.8$ & $3.2 \pm 1.0$ & $<0.001$ \\
$\begin{array}{l}\text { Hospital stay, days } \\
\quad \text { mean } \pm \text { SD) }\end{array}$ & $7.4 \pm 1.9$ & $8.9 \pm 4.0$ & 0.004 \\
$\begin{array}{l}\text { Reoperation } \\
\text { Morbidity }\end{array}$ & $1(1.4)$ & $2(2.1)$ & 0.820 \\
$\quad$ Grade I & $9(12.2)$ & $12(12.5)$ & 0.947 \\
$\quad$ Grade II & $2(2.7)$ & $2(2.1)$ & 0.804 \\
$\quad$ Grade III & $5(6.8)$ & $6(6.3)$ & 0.855 \\
Mortality & $2(2.7)$ & $4(4.2)$ & 0.924 \\
\hline
\end{tabular}

Numbers in parentheses are percentages

ED group early diet group, $C D$ group conventional diet group

a Severities of complications were based on the Clavien-Dindo classification of surgical complication [16]

\section{Postoperative outcomes}

Table 2 summarizes postoperative outcomes in the two study groups. Average diet start times (postoperative days) for the ED was 1.8 days and 3.2 days for the CD groups, and this difference was statistically significant $(p<0.001)$. Mean hospital stay of the ED group was 7.4 days, which was significantly shorter than 8.9 days of the $\mathrm{CD}$ group $(p=0.004)$. Postoperative morbidity rates were similar (12.2 vs. $12.5 \%, p=0.947$ ) between the two groups, and no mortality occurred in either group. Of the complications, no significant intergroup difference was found with respect to the rates gastrointestinal-related complications, such as anastomosis leakage, anastomosis bleeding, paralytic ileus, or intestinal obstruction (Table 3).

To evaluate the adaptation of patients to early postoperative oral diet, we measured the amount of meal that patients can consume every day. Figure 2 shows the percentages of patients who could eat more than two-thirds of given meals at different times after surgery. In the ED group, more than $70 \%$ of patients consumed more than two-thirds of given meals from the third postoperative day, whereas in the $\mathrm{CD}$ group this occurred on the fifth postoperative day.

Table 4 summarizes comparisons of postoperative outcomes in the two groups subdivided by operation type, that is, extent of gastric resection, operative approach, and extent of lymph node dissection. The table shows that patients in the ED group consistently showed earlier diet starts and shorter hospital stays than the $\mathrm{CD}$ group, although the statistical significances in hospital stay were not reached in some groups (total gastrectomy, open 
Table 3 Postoperative complications in the two study groups

\begin{tabular}{|c|c|c|c|c|c|}
\hline & \multicolumn{2}{|c|}{$\begin{array}{l}\text { ED group } \\
(n=74)\end{array}$} & \multicolumn{2}{|l|}{$\begin{array}{l}\text { CD group } \\
(n=96)\end{array}$} & \multirow[t]{2}{*}{$p$} \\
\hline & No. & $\begin{array}{l}\text { Grade } \\
\text { III }^{\mathrm{a}}\end{array}$ & No. & $\begin{array}{l}\text { Grade } \\
\text { III }^{\mathrm{a}}\end{array}$ & \\
\hline Local complications & $8(10.8)$ & $2(2.7)$ & $10(10.4)$ & $4(4.2)$ & 0.933 \\
\hline Luminal bleeding & 3 & 0 & 5 & 1 & 1.000 \\
\hline Abdominal bleeding & 2 & 0 & 1 & 1 & 0.820 \\
\hline Intestinal obstruction & 1 & 1 & 1 & 0 & 0.595 \\
\hline Paralytic ileus & 1 & 0 & 1 & 0 & 0.595 \\
\hline Abdominal abscess & 1 & 1 & 0 & 0 & 0.896 \\
\hline Pancreatic fistula & 0 & 0 & 1 & 1 & 0.896 \\
\hline Wound & 0 & 0 & 1 & 1 & 0.896 \\
\hline Systemic complications & $2(2.7)$ & 0 & $3(3.1)$ & 0 & 0.767 \\
\hline Pulmonary & 0 & 0 & 2 & 0 & 0.749 \\
\hline Renal & 1 & 0 & 0 & 0 & 0.896 \\
\hline Others & 1 & 0 & 1 & 0 & 0.595 \\
\hline
\end{tabular}

Numbers in parentheses are percentages

$E D$ group early diet group, $C D$ group conventional diet group

a Severity based on the Clavien-Dindo classification of surgical complications

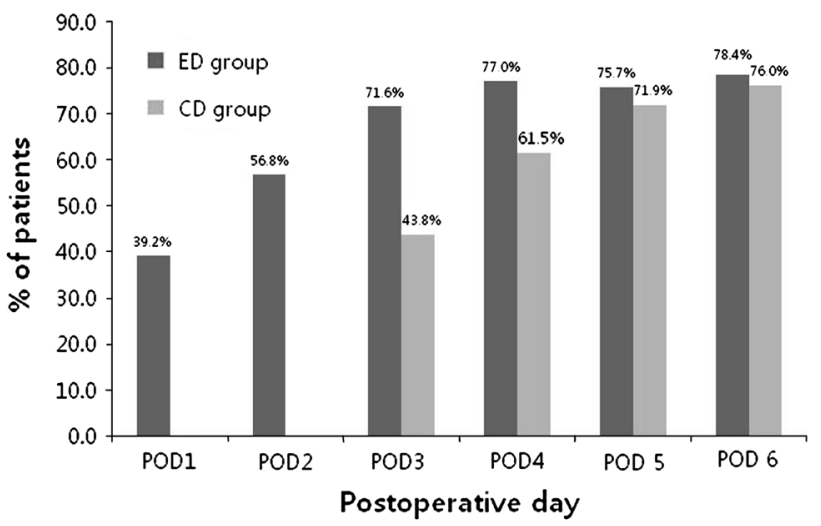

Fig. 2 Percentages of patients able to consume more than two-thirds of provided meals. In the early diet (ED) group, more than $70 \%$ of patients consumed more than two-thirds of meals provided from the third postoperative day, whereas this occurred from the fifth postoperative day in the conventional diet $(\mathrm{CD})$ group

surgery, and D2 lymph node dissection group) probably due to the small number of patients. However, there was no increase of postoperative morbidity in the ED group, regardless of the extent of gastric resection (total vs. distal), operative approach (open vs. laparoscopy), or extent of lymph node dissection (D1+ vs. D2).

Compliance with early oral nutrition

To evaluate compliance with early oral nutrition, we defined compliance as the ability to intake more than one-
Table 4 Subgroup analysis of postoperative outcomes by operation type

\begin{tabular}{|c|c|c|c|}
\hline & $\begin{array}{l}\text { Time to } \\
\text { oral diet } \\
\text { (days) }\end{array}$ & $\begin{array}{l}\text { Hospital } \\
\text { stay } \\
\text { (days) }\end{array}$ & $\begin{array}{l}\text { Morbidity } \\
(\%)\end{array}$ \\
\hline \multicolumn{4}{|l|}{ Gastric resection } \\
\hline \multicolumn{4}{|l|}{ Distal $(n=137)$} \\
\hline Early diet $(n=62)$ & $1.8 \pm 1.9$ & $7.4 \pm 2.0$ & $8(12.9)$ \\
\hline Conventional diet $(n=75)$ & $3.2 \pm 1.2$ & $9.2 \pm 5.3$ & $5(6.7)$ \\
\hline$p$ & $<0.001$ & 0.015 & 0.215 \\
\hline \multicolumn{4}{|l|}{ Total $(n=33)$} \\
\hline Early diet $(n=12)$ & $1.6 \pm 1.2$ & $7.3 \pm 1.0$ & $1(8.3)$ \\
\hline Conventional diet $(n=21)$ & $3.1 \pm 4.4$ & $9.3 \pm 3.6$ & $7(33.3)$ \\
\hline$p$ & 0.001 & 0.064 & 0.206 \\
\hline \multicolumn{4}{|l|}{ Operative approach } \\
\hline \multicolumn{4}{|l|}{ Open $(n=68)$} \\
\hline Early diet $(n=25)$ & $1.9 \pm 1.8$ & $7.9 \pm 2.6$ & $5(20.0)$ \\
\hline Conventional diet $(n=43)$ & $3.1 \pm 0.3$ & $10.1 \pm 6.8$ & $7(16.3)$ \\
\hline$p$ & 0.007 & 0.134 & 0.748 \\
\hline \multicolumn{4}{|l|}{ Laparoscopy $(n=102)$} \\
\hline Early diet $(n=49)$ & $1.7 \pm 1.8$ & $7.1 \pm 1.4$ & $4(8.2)$ \\
\hline Conventional diet $(n=53)$ & $3.3 \pm 1.4$ & $8.5 \pm 2.7$ & $5(9.4)$ \\
\hline$p$ & $<0.001$ & 0.002 & 1.000 \\
\hline \multicolumn{4}{|l|}{ Lymph node dissection } \\
\hline \multicolumn{4}{|l|}{$\mathrm{D} 1+(n=118)$} \\
\hline Early diet $(n=49)$ & $1.8 \pm 1.8$ & $7.4 \pm 1.7$ & $5(10.2)$ \\
\hline Conventional diet $(n=68)$ & $3.3 \pm 1.2$ & $8.9 \pm 4.3$ & $8(11.6)$ \\
\hline$p$ & $<0.001$ & 0.019 & 0.812 \\
\hline \multicolumn{4}{|l|}{ D2 $(n=52)$} \\
\hline Early diet $(n=25)$ & $1.8 \pm 1.8$ & $7.4 \pm 2.2$ & $4(16.0)$ \\
\hline Conventional diet $(n=27)$ & $3.0 \pm 0.7$ & $9.9 \pm 6.4$ & $4(14.8)$ \\
\hline$p$ & 0.004 & 0.073 & 1.000 \\
\hline
\end{tabular}

third of given meal without an adverse event. The intake of less than one-third of a given meal due to adverse gastrointestinal symptoms or therapeutic fasting for any reason was defined as non-compliance.

Of the 74 patients in the ED group, $58(78.4 \%)$ patients successfully started an early oral diet on the first postoperative day. Postoperative oral nutrition was delayed due to gastrointestinal symptoms in eight patients; anorexia $(n=2)$, nausea $(n=4)$, vomiting $(n=1)$, or abdominal fullness/distension $(n=2)$, or due to a diagnostic or treatment-related procedure for a postoperative complication in eight patients.

Table 5 shows the results of the analysis conducted to identify factors affecting compliance with early oral nutrition. It was found that an old age ( $\geq 70$ years) was significantly associated with non-compliance, whereas gender, ASA score, resection type, operative approach, extent of lymphadenectomy, operating time, and combined resection 
Table 5 Factors affecting compliance to early oral nutrition

\begin{tabular}{|c|c|c|c|}
\hline & $\begin{array}{l}\text { Patients } \\
(n=74)\end{array}$ & $\begin{array}{l}\text { Non-compliance } \\
(n=16)\end{array}$ & $p$ \\
\hline \multicolumn{3}{|l|}{ Age (years) } & 0.031 \\
\hline$<70$ & 59 & $10(16.9)$ & \\
\hline$\geq 70$ & 15 & $6(40.0)$ & \\
\hline \multicolumn{3}{|l|}{ Gender } & 1.000 \\
\hline Male & 54 & $12(22.2)$ & \\
\hline Female & 20 & $4(20.0)$ & \\
\hline \multicolumn{3}{|l|}{ ASA score } & 0.187 \\
\hline 1 & 24 & $3(12.5)$ & \\
\hline $2-3$ & 50 & $13(26.0)$ & \\
\hline \multicolumn{3}{|l|}{ Resection type } & 0.715 \\
\hline Total gastrectomy & 112 & $3(25.0)$ & \\
\hline Distal gastrectomy & 62 & $13(21.0)$ & \\
\hline \multicolumn{3}{|l|}{ Operative approach } & 0.341 \\
\hline Open & 25 & $7(28.0)$ & \\
\hline Laparoscopy & 49 & $9(18.4)$ & \\
\hline \multicolumn{3}{|l|}{ Lymphadenectomy } & 0.809 \\
\hline $\mathrm{D} 1+$ & 49 & $11(22.4)$ & \\
\hline D2 & 25 & $5(20.0)$ & \\
\hline \multicolumn{3}{|l|}{ Operating time (min) } & 0.809 \\
\hline$<140$ & 49 & $11(22.4)$ & \\
\hline$\geq 140$ & 25 & $5(20.0)$ & \\
\hline \multicolumn{3}{|c|}{ Combined organ resection } & 0.604 \\
\hline Absent & 68 & $14(20.6)$ & \\
\hline Present & 6 & $2(33.3)$ & \\
\hline \multicolumn{4}{|l|}{ Tumor stage } \\
\hline Early & 46 & $8(17.4)$ & 0.257 \\
\hline Advanced & 28 & 8 (28.6) & \\
\hline
\end{tabular}

Numbers in parentheses are percentages

$O R$ odds ratio, $C I$ confidence interval

were not. Of the 15 elderly patients ( $\geq 70$ years) in the ED group, two patients stopped early oral nutrition due to postoperative complication (abdominal bleeding and luminal bleeding), and four patients, due to adverse gastrointestinal symptoms. All of these patients resumed oral diet within postoperative day 5 with conservative care. No serious adverse events related early oral diet, such as anastomosis leakage or aspiration pneumonia, occurred in these patients.

\section{Discussion}

In patients that have undergone colorectal surgery, early postoperative enteral nutrition has been reported to reduce postoperative morbidity and mortality and hospital stay, and as a result, early postoperative enteral nutrition is widely believed to enhance postoperative recovery [18]. However, several institutions in Asia and Europe still adhere to 3-4 days of postoperative fasting after gastrectomy due to concerns about the feasibility and safety of an early postoperative oral diet $[10,11]$. Nonetheless, the present study shows that early postoperative oral nutrition can be initiated as early as on the first postoperative day after gastrectomy without increasing postoperative morbidity, including gastrointestinal-related complications or aspiration pneumonia. Furthermore, our findings also suggest that early postoperative oral nutrition may reduce hospital stays by enhancing adaptation to postoperative oral diet in patients that have undergone gastric resection. The present study suggests that early oral nutrition on the first postoperative day could be adopted in multimodal approaches for enhancing postoperative recovery after gastrectomy. However, additional studies will be required to demonstrate its clinical benefits, for example, with respect to nutritional status, postoperative recovery, or quality of life.

Traditional concerns about the safety of gastrointestinal anastomosis prevented surgeons from accepting early postoperative oral nutrition after gastrectomy. For this reason, in the previous studies on early enteral nutrition after esophagogastric surgery, enteral nutrition was often administered via an intestinal tube (naso-jejunal tube or catheter jejunostomy) to protect anastomosis [19-22]. However, several experimental and clinical studies have demonstrated that early enteral feeding increases wound healing and anastomotic strength in intestines and somatic tissues [23, 24]. In the present study, no member of the ED group developed anastomosis leakage, and any other gastrointestinal-related complication, such as, anastomosis bleeding, paralytic ileuses, or intestinal obstruction, were no higher than the $\mathrm{CD}$ group. Therefore, it appears that concerns about anastomosis safety and adverse gastrointestinal symptoms do not justify the avoidance of immediate postoperative oral nutrition in patients after gastrectomy.

Postoperative ileus is known to be predominantly of neural and inflammatory origin and is considered to undermine the tolerance to an early oral diet [25]. Therefore, we should emphasize that the successful implementation of early oral nutrition require a multimodal approach to enhance recovery from postoperative ileus. For example, Lobo et al. [26] have demonstrated excessive postoperative fluid administration significantly delays the return of gastrointestinal function and prolongs hospital stay in patients undergoing elective colonic resection. In our study, intravenous fluid was restricted to a minimal requirement of $20-25 \mathrm{ml} / \mathrm{kg} /$ day of parenteral nutritional solution during the first three postoperative days. In addition to this, minimally invasive procedures, effective epidural analgesia, short-acting intraoperative opioids, avoidance of preoperative bowel cleansing, selective use of abdominal drainage 
and a nasogastric tube, and enforced postoperative ambulation have also been suggested to be key elements for enhancing recovery [7]. These approaches were all integrated well into our perioperative care protocol for patients with early oral nutrition, and we believe that this combined approach significantly contributed to the successful implementation of early oral nutrition in our patients.

Some authors have advocated the benefits and feasibility of early oral nutrition after gastrectomy, but relatively few have evaluated early oral nutrition started on the first postoperative day. In 2004, Suehiro et al. [13] first reported early oral feeding within $48 \mathrm{~h}$ of gastrectomy reduced hospital stay as compared with conventional postoperative fasting; postoperative morbidities and mortalities, including nausea, vomiting, anastomotic leakage, and wound infections were similar in their two groups. In 2005, Hirao et al. [12] introduced the "patient-controlled diet schedule" for patients that undergo gastrectomy, according to which a solid diet is supplied on patient demand from the third postoperative day. As compared with a fixed diet regimen requiring that a solid diet be started on the 10th postoperative day, patients showed shorter hospital stays and no increase in morbidity or mortality. More recently, Hur et al. [14] reported the results of a small randomized trial, in which early oral feeding on the second postoperative day significantly enhanced bowel recovery, reduced hospital stay, and improved some elements of quality of life. In a large randomized controlled trial by Lassen et al. [27], 453 patients, including 159 gastrectomy cases, were assigned to a routine nil-by mouth and enteral tube feeding by needlecatheter jejunostomy or normal food at will from the first postoperative day after major upper gastrointestinal surgery. In their study, no differences were found with respect to postoperative morbidity and mortality, but the recovery of bowel function was significantly improved in the early diet group. In addition, in one study about "fast-track surgery" in patients with gastric cancer, Wang et al. [28] introduced oral nutrition on the first postoperative day and found that hospital stays and medical costs were reduced and quality of life was improved. Unlike the study by Wang et al., the present study more specifically focused on the early oral feeding after gastrectomy. Despite the retrospective study design, it was aimed at evaluating the feasibility and safety of the early oral feeding. The compliance and possible risks by early oral feeding were examined in detail.

In the present study, patients in the ED group were found to have significantly reduced hospital stay than the CD group. At our institution, hospital discharge is based on the fulfillment of objective recovery criteria, but inevitably the decisions made are somewhat subjective. Nevertheless, the ability to eat a sufficient amount of given meal without adverse gastrointestinal symptoms is a key determinant of duration post-gastrectomy. Our discharge criteria included the ability to eat more than half of given meal without adverse gastrointestinal symptoms. In the present study, the finding of reduced hospital stay in the ED group is probably due to the fact that $>70 \%$ of patients consumed more than two-thirds of given meals from the third postoperative day, which was significantly earlier than that of the $C D$ group (Fig. 2). This finding suggests that early oral nutrition may enhance early adaptation to postoperative oral intake after gastric resection. However, the beneficial effects of early oral nutrition on postoperative recovery and hospital stay require to be further evaluated in welldesigned clinical trials.

The feasibility of early oral nutrition does not seem to depend on operation type. Subgroup analysis showed that the ED group showed no increase of postoperative morbidity rates, regardless of the extent of gastric resection or lymph node dissection, or the operative approach. Although, more studies are required in specific patient subgroups, our findings indicate that early oral nutrition can be applied to gastric cancer surgery regardless of type of resection, lymph node dissection, or operative approach. Nevertheless, compliance with early oral nutrition was found to be significantly poorer in older patients, especially in those more than 70 years of age. In the analysis of factors affecting the compliance to early oral feeding, univariate analysis revealed that an old age was found to be significantly associated with non-compliance to early oral feeding. This finding indicates early oral nutrition might be difficult in the elderly, and that it should be applied with caution to prevent adverse gastrointestinal symptoms related to oral nutrition.

Preoperative carbohydrate administration is also an important nutritional and metabolic part of multimodal approaches for enhancing recovery after surgery, and the current guidelines commonly recommend this as a main element of ERAS program. Several studies have demonstrated that preoperative carbohydrate rich drink $2 \mathrm{~h}$ before surgery reduces postoperative insulin resistance, preserve skeletal muscle mass, and improves well-being sense [29, 30]. At our institution, preoperative carbohydrate administration is currently being performed as a routine practice for patients undergoing gastrectomy, but it was not applied during the study period.

Several limitations of this study deserve consideration. First, this was a historical case-control study conducted without blinding investigators, and patients were not randomly allocated. Therefore, bias with respect to patient selection and outcome assessments is inevitable-despite the comparable baseline characteristics of the two groups. Second, this study does not provide sufficient data 
regarding the effects of early oral nutrition on clinical or physiologic criteria, such as, insulin resistance, nutritional status, postoperative recovery, or quality of life. Randomized controlled trials with appropriate parameters and endpoints should be conducted to clarify the benefits of early oral nutrition.

Summarizing, starting oral nutrition on the first postoperative day was found to be feasible and safe after gastrectomy. Furthermore, our findings also suggest that early oral nutrition may reduce hospital stays by enhancing adaptation to oral intake. In addition, early oral nutrition was found to be feasible regardless of type of gastric resection, lymph node dissection, or operative approach. On the other hand, an age of $>70$ years was found to compromise compliance with early oral nutrition significantly. We suggest that randomized controlled trials be initiated to clarify the benefits of early oral nutrition with respect to clinical outcomes, such as, nutritional status, postoperative recovery, and quality of life.

Acknowledgments No financial or material support was received for this study.

\section{References}

1. Wilmore DW. Metabolic response to severe surgical illness: overview. World J Surg. 2000;24:705-11.

2. Kudsk KA, Croce MA, Fabian TC, Minard G, Tolley EA, Poret HA, et al. Enteral versus parenteral feeding. Effects on septic morbidity after blunt and penetrating abdominal trauma. Ann Surg. 1992;215:503-11 (discussion 511-3).

3. Moore EE, Jones TN. Benefits of immediate jejunostomy feeding after major abdominal trauma - a prospective, randomized study. J Trauma. 1986;26:874-81.

4. Lewis SJ, Andersen HK, Thomas S. Early enteral nutrition within $24 \mathrm{~h}$ of intestinal surgery versus later commencement of feeding: a systematic review and meta-analysis. J Gastrointest Surg. 2009;13:569-75.

5. Mazaki T, Ebisawa K. Enteral versus parenteral nutrition after gastrointestinal surgery: a systematic review and meta-analysis of randomized controlled trials in the English literature. J Gastrointest Surg. 2008;12:739-55.

6. Osland E, Yunus RM, Khan S, Memon MA. Early versus traditional postoperative feeding in patients undergoing resectional gastrointestinal surgery: a meta-analysis. JPEN. 2011;35:473-87.

7. Kehlet H, Wilmore DW. Multimodal strategies to improve surgical outcome. Am J Surg. 2002;183:630-41.

8. Kehlet H, Wilmore DW. Evidence-based surgical care and the evolution of fast-track surgery. Ann Surg. 2008;248:189-98.

9. Andersen H, Lewis S, Thomas S. Early enteral nutrition within $24 \mathrm{~h}$ of colorectal surgery versus later commencement of feeding for postoperative complications. Cochrane Database Syst Rev. 2006;4:CD004080.

10. Ahn HS, Yook JH, Park CH, Park YK, Yu W, Lee MS, et al. General perioperative management of gastric cancer patients at high-volume centers. Gastric Cancer. 2011;14:178-82.

11. Lassen K, Dejong $\mathrm{CH}$, Ljungqvist $\mathrm{O}$, Fearon K, Andersen J, Hannemann $\mathrm{P}$, et al. Nutritional support and oral intake after gastric resection in five northern European countries. Dig Surg. 2005;22:346-52 (discussion 352).

12. Hirao M, Tsujinaka T, Takeno A, Fujitani K, Kurata M. Patientcontrolled dietary schedule improves clinical outcome after gastrectomy for gastric cancer. World J Surg. 2005;29:853-7.

13. Suehiro T, Matsumata T, Shikada Y, Sugimachi K. Accelerated rehabilitation with early postoperative oral feeding following gastrectomy. Hepatogastroenterology. 2004;51:1852-5.

14. Hur H, Kim SG, Shim JH, Song KY, Kim W, Park CH, et al. Effect of early oral feeding after gastric cancer surgery: a result of randomized clinical trial. Surgery. 2011;149:561-8.

15. Jung MR, Park YK, Seon JW, Kim KY, Cheong O, Ryu SY. Definition and classification of complications of gastrectomy for gastric cancer based on the accordion severity grading system. World J Surg. 2012;36:2400-11.

16. Dindo D, Demartines N, Clavien PA. Classification of surgical complications: a new proposal with evaluation in a cohort of 6336 patients and results of a survey. Ann Surg. 2004;240:205-13.

17. Japanese Gastric Cancer Association. Japanese gastric cancer treatment guidelines 2010 (ver. 3). Gastric Cancer. 2011;14:113-23.

18. Dervenis C, Avgerinos C, Lytras D, Delis S. Benefits and limitations of enteral nutrition in the early postoperative period. Langenbecks Arch Surg. 2003;387:441-9.

19. Baigrie RJ, Devitt PG, Watkin DS. Enteral versus parenteral nutrition after oesophagogastric surgery: a prospective randomized comparison. Aust N Z J Surg. 1996;66:668-70.

20. Gianotti L, Braga M, Vignali A, Balzano G, Zerbi A, Bisagni P, et al. Effect of route of delivery and formulation of postoperative nutritional support in patients undergoing major operations for malignant neoplasms. Arch Surg. 1997;132:1222-30.

21. Heslin MJ, Latkany L, Leung D, Brooks AD, Hochwald SN, Pisters PW, et al. A prospective, randomized trial of early enteral feeding after resection of upper gastrointestinal malignancy. Ann Surg. 1997;226:567-77 (discussion 577-80).

22. Bozzetti F, Braga M, Gianotti L, Gavazzi C, Mariani L. Postoperative enteral versus parenteral nutrition in malnourished patients with gastrointestinal cancer: a randomised multicentre trial. Lancet. 2001;358:1487-92.

23. Moss G, Greenstein A, Levy S, Bierenbaum A. Maintenance of GI function after bowel surgery and immediate enteral full nutrition. I. Doubling of canine colorectal anastomotic bursting pressure and intestinal wound mature collagen content. JPEN. 1980;4:535-8.

24. Schroeder D, Gillanders L, Mahr K, Hill GL. Effects of immediate postoperative enteral nutrition on body composition, muscle function, and wound healing. JPEN. 1991;15:376-83.

25. Bisgaard T, Kehlet H. Early oral feeding after elective abdominal surgery-what are the issues? Nutrition. 2002;18:944-8.

26. Lobo DN, Bostock KA, Neal KR, Perkins AC, Rowlands BJ, Allison SP. Effect of salt and water balance on recovery of gastrointestinal function after elective colonic resection: a randomized controlled trial. Lancet. 2002;359:1812-8.

27. Lassen K, Kjaeve J, Fetveit T, Trano G, Sigurdsson HK, Horn A, et al. Allowing normal food at will after major upper gastrointestinal surgery does not increase morbidity: a randomized multicenter trial. Ann Surg. 2008;247:721-9.

28. Wang D, Kong Y, Zhong B, Zhou X, Zhou Y. Fast-track surgery improves postoperative recovery in patients with gastric cancer: a randomized comparison with conventional postoperative care. J Gastrointest Surg. 2010;14:620-7.

29. Li L, Wang Z, Ying X, Tian J, Sun T, Yi K, et al. Preoperative carbohydrate loading for elective surgery: a systemic review and meta-analysis. Surg Today. 2012;42:613-24.

30. Ljungqvist $\mathrm{O}$. Modulating postoperative insulin resistance by preoperative carbohydrate loading. Best Pract Res Clin Anaesthesiol. 2009;23:401-9. 